\title{
Progress requires change from the norm
}

It is a pleasure to write this short introduction to this special edition of Clinical Medicine. This change of style from the normal edition of the journal is planned as a regular annual feature for the last edition of each year. The focus of this year is perioperative medicine, and was originally inspired by the launch of the Centre for Perioperative Care based in the Royal College of Anaesthetists (RCOA). We are delighted to showcase a sequence of state-of-theart manuscripts aimed at practicing clinicians in the acute setting, jointly authored by physicians and anaesthesiologists/intensivists. Covering a range of topics, this edition - like all future themed ones - is aimed to cut across specialties and provide value to all physicians. The material is wide ranging: there are articles that will be of great help the medical registrar (perioperative diabetic care, opioid management, management of surgery in frail individuals) as well as manuscripts to help with system design (in the context of integrated care systems, 'prehabilitation' initiatives, shared decision making). ${ }^{1-6}$ The content has been invited and carefully curated by Dorian Martinez, James Goodwin, David Selwyn and many others from the RCoA who, along with the authors, deserve all the credit for this issue.

A further initiative to highlight is the new Royal College of Physicians' journals website. Clinical Medicine and Future Healthcare Journal can now be accessed via our new site (www. rcpjournals.org) which offers an improved experience for readers with a clean design to access both current articles and our archive. The new layout optimises access to the images and clinical cases which will update on a monthly basis. In addition, we will have a publish ahead of print facility on the new site, representing a significant advantage for both authors and readers in terms of getting content out into the public domain quicker. Finally, the impact factor (IF) of the journal has risen from 1.632 to 2.046 , thanks to strong content and the hard work of the journal's publishing team. While we are not focused on IF as a primary sign of ClinMed's clinical impact, we hope that an impact factor over 2 will attract more authors to submit their best work to us.

\section{References}

1 Dhatariya K, Levy N. Perioperative diabetes care. Clin Med 2019;19:437-40.

2 Quinlan J, Rann S, Bastable R, Levy N. Perioperative opioid use and misuse. Clin Med 2019;19:441-5.

3 Dhesi JK, Lees NP, Partridge JSL. Frailty in the perioperative setting. Clin Med 2019;19:485-9.

4 Bougeard A-M, Moore J. Delivering perioperative medicine in integrated care systems. Clin Med 2019;19:450-3.

5 Durrand J, Danjoux G, Singh S. Prehabilitation. Clin Med 2019; 19:458-64.

6 Swart M, McCarthy R. Shared decision making for elective abdominal aortic aneurysm surgery. Clin Med 2019;19:473-7.

Anton Emmanuel Editor-in-chief

$\begin{array}{llll}\text { Members of the editorial board } & & & \\ \text { Michael Almond } & \text { Anton Emmanuel } & \text { Yash Mahida } & \text { Roby Rakhit } \\ \text { Cono Ariti } & \text { Kate Evans } & \text { Nick Manning-Cork } & \text { Avan Sayer } \\ \text { Paul Belcher } & \text { Johanna Feary } & \text { Chris Marguerie } & \text { Philip Smith } \\ \text { Rodger Charlton } & \text { Maggie Hammersley } & \text { Martin McKee } & \text { Angela Star } \\ \text { Tim Chevassut } & \text { Dylan Harris } & \text { Andrew Medford } & \text { Cameron Swift } \\ \text { Tahseen Chowdhury } & \text { Tevfik Ismail } & \text { Rahul Mukherjee } & \text { Rhys Thomas } \\ \text { Elaine Dennison } & \text { Vikas Kapil } & \text { Mehool Patel } & \\ \text { Albert Edwards } & \text { Alexandra Lake } & \text { Gerrard Phillips } & \end{array}$

